\title{
Produção de forragem e valor nutritivo do capim-elefante, irrigado durante a época seca
}

\author{
Antônio Carlos Cóser ${ }^{(1)}$, Carlos Eugênio Martins ${ }^{(2)}$, Fermino Deresz ${ }^{(2)}$, Ary Ferreira de Freitas ${ }^{(2)}$, \\ Domingos Sávio Campos Paciullo( ${ }^{(2)}$, Carlos Augusto Brasileiro de Alencar ${ }^{(3)}$ e Cláudio Manoel Teixeira Vítor ${ }^{(4)}$
}

\begin{abstract}
(1)Avenida José Procópio Teixeira, no 418/301, CEP 36021-540 Juiz de Fora, MG. E-mail: acoser1@yahoo.com.br (2)Embrapa Gado de Leite, Rua Eugênio do Nascimento, no 610, Dom Bosco, CEP 36038-330 Juiz de Fora, MG. E-mail: caeuma@cnpgl.embrapa.br, deresz@cnpgl.embrapa.br, ary@cnpgl.embrapa.br, domingos@cnpgl.embrapa.br (3)Universidade Vale do Rio Doce, Campus Antônio Rodrigues Coelho, Caixa Postal 295, CEP 35020-220 Governador Valadares, MG. E-mail: brasileiro@univale.br ${ }^{(4)}$ Empresa de Pesquisa Agropecuária de Minas Gerais, Fazenda Experimental de Nova Porteirinha, Caixa Postal 12, CEP 39525-000 Nova Porteirinha, MG. E-mail: cmtvitor@epamig.gov.br
\end{abstract}

Resumo - O objetivo deste trabalho foi avaliar o efeito da irrigação, na época seca do ano, sobre as características produção de matéria seca, altura das plantas, cobertura do solo e a qualidade de forragem do capim-elefante (Pennisetum purpureum). O experimento foi realizado em Coronel Pacheco, MG, de junho/2004 a janeiro/2007, e os tratamentos foram: irrigações a partir de 15/7, 1\%/8, 15/8, 1\%/9, 15/9 e 1\%/10, com adubação de $300 \mathrm{~kg} \mathrm{ha}^{-1}$ de N por ano; com dois tratamentos sem irrigação, adubados com 300 e $200 \mathrm{~kg} \mathrm{ha}^{-1}$ de $\mathrm{N}$ por ano. Foram usados dois métodos de colheita: corte a $10 \mathrm{~cm}$ do solo e pastejo simulado, realizado acima da altura de resíduo (80-100 cm). A produção de matéria seca e a altura das plantas aumentaram com as irrigações iniciadas em julho e agosto. As pastagens irrigadas a partir de julho e agosto atingiram condições de pastejo quatro a seis semanas antes que as dos tratamentos não irrigados. A produção de matéria seca obtida pelo método do corte foi duas vezes superior àquela obtida pelo pastejo simulado. Os teores de proteína bruta e a digestibilidade in vitro da matéria seca foram maiores no pastejo simulado do que no corte, mas os teores de fibra em detergente neutro foram semelhantes.

Termos para indexação: Pennisetum purpureum, gramíneas tropicais, irrigação estratégica, produção de forragem, qualidade.

\section{Dry matter yield and nutritive value of elephantgrass irrigated during the dry season}

\begin{abstract}
The objective of this work was to evaluate irrigation strategies on elephantgrass (Pennisetum purpureum) pasture, during the dry season, upon dry matter yield, plant height, ground cover, and forage quality. The experiment was conducted in the county of Coronel Pacheco, Minas Gerais, Brazil, from June/2004 to January/2007. The treatments evaluated were: treatments with irrigation starting on Jul. 15, Aug. st $^{\text {st }}$ Aug. 15, Sept. ${ }^{\text {st }}$, Sept. 15, and Oct. $1^{\text {st }}$ fertilized with $300 \mathrm{~kg} \mathrm{ha}^{-1}$ of N per year, and two control treatments (without irrigation) fertilized with 300 and $200 \mathrm{~kg} \mathrm{ha}^{-1}$ of $\mathrm{N}$ per year. Two harvest methods were used: hand plucking maintaining a forage stubble height of $80-100 \mathrm{~cm}$ and cutting at $10 \mathrm{~cm}$ above the soil surface. Both dry matter yield and plant height increased with the earliness of irrigation onset. Pastures with irrigation onset in July and August were ready for grazing four to six weeks earlier than those without irrigation. Dry matter yield obtained by cutting was double that obtained by hand plucking. Crude protein content and in vitro dry matter digestibility were higher with hand plucking than by cutting, but neutral detergent fiber contents were similar.
\end{abstract}

Index terms: Pennisetum purpureum, tropical grasses, strategic irrigation, forage yield, quality.

\section{Introdução}

O capim-elefante (Pennisetum purpureum Schum.) é uma das forrageiras mais adaptadas aos sistemas intensivos de produção de leite em pasto, em razão de seu elevado potencial produtivo e sua qualidade. Resultados de pesquisa com capim-elefante têm indicado a possibilidade de obtenção de produções de leite de $12 \mathrm{~kg}$ por vaca por dia, com taxas de lotação de 4 a 6 UA ha $^{-1}$, durante a época chuvosa, em sistemas não irrigados (Cóser et al., 1999; Deresz, 2001; Deresz et al., 2001; Carvalho et al., 2005).

As regiões fisiográficas do Brasil apresentam, em geral, duas estações climáticas bem distintas: a chuvosa, em que a umidade, a temperatura e a luminosidade são geralmente favoráveis ao crescimento das espécies 
tropicais, e a da seca, em que esses fatores são limitantes. Como conseqüência, ocorre marcante estacionalidade anual de produçãode forragem, cujos efeitos sãominimizados pelo fornecimento de suplementos volumosos e concentrados nessa época (Aroeira et al., 1999).

A irrigação na época seca tem sido apontada como opção para se minimizar o efeito da sazonalidade da produção forrageira, desde que os fatores climáticos, especialmente temperatura e luminosidade, não sejam limitantes. Em geral, trabalhos com irrigação, na época seca do ano, mostram efeito sobre a produção de forragem, sem influenciar a sua estacionalidade (Botrel et al., 1991; Lopes et al., 2003; Rassini et al., 2004). Botrel et al. (1991) afirmaram que o fornecimento de água, durante a época de estiagem, também não influenciou a qualidade da forragem produzida. Palieraqui (2004) e Ribeiro (2004) relataram que a prática da irrigação em pastagens apresenta grande potencial em Campos dos Goytacazes, no Norte do Estado do Rio de Janeiro.

A composição química e a digestibilidade das plantas forrageiras variam, entre outros fatores, com a espécie, o estádio de maturidade e fatores climáticos (Gerdes et al., 2000; Deresz, 2001; Paciullo et al., 2001). Plantas submetidas à condição adequada de umidade no solo têm seu desenvolvimento ontogênico acelerado, em comparação com as submetidas ao deficit hídrico (Dias Filho et al., 1991). Assim, em uma mesma idade cronológica, as plantas irrigadas tendem a ser fisiologicamente mais velhas do que as plantas não irrigadas, o que repercute na qualidade da forrageira, pois as alterações nos teores de fibra em detergente neutro e proteína das gramíneas estão relacionadas ao estádio fisiológico da planta (Paciullo et al., 2001; Carvalho et al., 2005).
A eficiência de utilização das plantas forrageiras pelos animais depende da qualidade e da quantidade de forragem disponível na pastagem, além do potencial genético do animal. Assim, quando a disponibilidade de forragem e o potencial do animal não são limitantes, a produção por animal é definida pela qualidade da forragem e está diretamente relacionada ao consumo voluntário e à disponibilidade dos nutrientes nela contidos.

Ainda são escassas as informações sobre o uso de pastagens de capim-elefante submetidas à irrigação. Informações sobre o manejo da irrigação, para o estabelecimento e a manutenção em áreas sob irrigação, são importantes.

O objetivo deste trabalho foi avaliar o efeito de estratégias de irrigação, na época seca do ano, sobre a produção de matéria seca, a altura das plantas, a cobertura do solo, a composição química e a digestibilidade in vitro da matéria seca do capim-elefante, por meio de dois métodos de avaliação de plantas forrageiras.

\section{Material e Métodos}

O experimento foi conduzido no Município de Coronel Pacheco $\left(21^{\circ} 33^{\prime} 22^{\prime \prime S}\right.$ e $43^{\circ} 6^{\prime} 15^{\prime \prime} \mathrm{W}$ e altitude de $410 \mathrm{~m}$ ), na região da Zona da Mata mineira, em solo do tipo Cambissolo Vermelho-Amarelo, de junho de 2004 a janeiro de 2007. O clima da região, conforme Köppen, é do tipo Cwa (mesotérmico). Os dados climáticos, relativos ao período experimental, foram coletados na Estação Meteorológica do Campo Experimental de Coronel Pacheco, MG, a cerca de $200 \mathrm{~m}$ da área experimental (Tabela 1). Foi usada uma área de capim-elefante cultivar. Napier estabelecida há seis anos. Para o início

Tabela 1. Valores médios mensais de precipitação pluvial (PP, mm), temperatura máxima (Tmáx, $\left.{ }^{\circ} \mathrm{C}\right)$, temperatura mínima (Tmín, ${ }^{\circ} \mathrm{C}$ ) e número de horas de insolação (Nhin, lux), em 2004, 2005 e 2006.

\begin{tabular}{|c|c|c|c|c|c|c|c|c|c|c|c|c|}
\hline Variáveis & Jan. & Fev. & Mar. & Abr. & Maio & Jun. & Jul. & Ago. & Set. & Out. & Nov. & Dez. \\
\hline \multicolumn{13}{|c|}{2004} \\
\hline PP & 349,5 & 418,9 & 215,4 & 152,9 & 31,4 & 39,2 & 33,9 & 0,2 & 1,7 & 87,2 & 194 & 480,8 \\
\hline Tmáx & 28,5 & 28,7 & 28,8 & 27,6 & 25,4 & 24,3 & 23,4 & 26 & 29,4 & 27,2 & 28,1 & 28,2 \\
\hline Tmín & 19,4 & 19,4 & 18,5 & 18,4 & 14,9 & 12,1 & 12,6 & 11 & 14,1 & 17,2 & 17,9 & 19,6 \\
\hline Nhin & - & 104,1 & 199 & 160,4 & 148,2 & 169,8 & 159,4 & 247,2 & 237,7 & 127,5 & 162,5 & 119,2 \\
\hline \multicolumn{13}{|c|}{2005} \\
\hline PP & 393,7 & 187,9 & 304,7 & 55,8 & 74,8 & 33,7 & 24,4 & 22,7 & 50,8 & 66,6 & 161,9 & 347,3 \\
\hline Tmáx & 29,2 & 30 & 29,6 & 29,2 & 26,6 & 25,1 & 24,3 & 26,9 & 25,9 & 30,4 & 27 & 28,3 \\
\hline Tmín & 20,3 & 19,2 & 20,1 & 19 & 15,4 & 13,3 & 12 & 12,8 & 16,2 & 17,3 & 18,4 & 18,2 \\
\hline Nhin & 129,3 & 186 & 187,7 & 227,9 & 195,1 & 179,2 & 180,1 & 234,5 & 111,3 & 200,9 & 90,1 & 136,7 \\
\hline \multicolumn{13}{|c|}{2006} \\
\hline PP & 108,6 & 295,4 & 159,1 & 50,1 & 37,4 & 7,1 & 7,6 & 59,9 & 53,4 & 160 & 249,6 & 228,1 \\
\hline Tmáx & 31,1 & 31,7 & 30,2 & 28,2 & 25,6 & 24,6 & 26,3 & 27,2 & 25,9 & 27,4 & 28 & 29,2 \\
\hline Tmín & 19,5 & 19,7 & 19,8 & 17,3 & 13,1 & 11,4 & 9,4 & 12,1 & 14 & 18,3 & 18,9 & 20,3 \\
\hline Nhin & 231,6 & 197,7 & 197,7 & 188,6 & 207,2 & 187,7 & 222,1 & 216,7 & 143,6 & 134,0 & 117,5 & 108,6 \\
\hline
\end{tabular}


do estudo, foi realizado um corte de uniformização no pasto, a $10 \mathrm{~cm}$ do solo, em 15/6/2004.

Foram avaliados os efeitos de diferentes datas de início das irrigações das pastagens, durante o período seco na região, que foram: 15/7 $\left(\mathrm{T}_{1}\right), 1 \% / 8\left(\mathrm{~T}_{2}\right), 15 / 8$ $\left(\mathrm{T}_{3}\right), 1 \% / 9\left(\mathrm{~T}_{4}\right), 15 / 9\left(\mathrm{~T}_{5}\right)$ e 1\%/10 $\left(\mathrm{T}_{6}\right)$, e dois tratamentos sem irrigação $\left(\mathrm{T}_{7}\right.$ e $\left.\mathrm{T}_{8}\right)$; o tratamento $\mathrm{T} 8$ foi incluído em 2005.

O delineamento experimental foi o de blocos ao acaso, em esquema de parcelas subdivididas, com quatro repetições. As datas de início da irrigação foram dispostas nas parcelas $(18 \times 18 \mathrm{~m})$, e os dois métodos de avaliação (pastejo simulado e corte) nas subparcelas (9x9 m), com quatro repetições. O uso da técnica do pastejo simulado foi feito para estimar a quantidade de forragem potencialmente consumível por animais em pastejo, conforme descrito por Cóser et al. (2003). O método do corte a $10 \mathrm{~cm}$ de altura da superfície do solo foi utilizado para se obterem informações referentes ao manejo de capineiras.

A adubação anual dos tratamentos de $\mathrm{T}_{1}$ a $\mathrm{T}_{7}$ constituiu-se de $300 \mathrm{~kg} \mathrm{ha}^{-1}$ de N, $50 \mathrm{~kg} \mathrm{ha}^{-1}$ de $\mathrm{P}_{2} \mathrm{O}_{5}$ e $200 \mathrm{~kg} \mathrm{ha}^{-1}$ de $\mathrm{K}_{2} \mathrm{O}$, à base de uréia, superfosfato simples e cloreto de potássio, respectivamente. $\mathrm{O}$ tratamento $\mathrm{T}_{8}$ recebeu $200 \mathrm{~kg} \mathrm{ha}^{-1}$ por ano de $\mathrm{N} \mathrm{e}$ de $\mathrm{K}_{2} \mathrm{O}$, e $50 \mathrm{~kg} \mathrm{ha}^{-1}$ por ano de $\mathrm{P}_{2} \mathrm{O}_{5}$. A adubação foi parcelada em seis aplicações iguais, a cada 60 dias, exceto em 2006, quando foram realizadas apenas cinco aplicações.

Foi usado o sistema de irrigação por aspersão, em malha com baixa pressão, recomendado por Alencar (1999). A reposição de água ao solo era realizada quando a disponibilidade de água no solo se aproximava de $50 \%$ da capacidade de campo, estimada por meio de leituras diárias de um conjunto de seis tensiômetros por parcela.

O manejo do capim-elefante foi realizado com dois métodos de amostragem: corte a $10 \mathrm{~cm}$ de altura, a cada 60 dias, e pastejo simulado quando uma das parcelas atingia entre 1,60 e 1,80 $\mathrm{m}$ de altura, o que representava, em média, 30 dias de intervalo de colheita.

Nos três anos, foram realizadas avaliações para a estimativa da massa de matéria seca em: $31 / 7,17 / 8$, 1\%/9, 15/9, 1\%/10 e 15/10, pela técnica do pastejo simulado (Cóser et al., 2003). Foram removidos, manualmente, folhas e colmos macios (forragem potencialmente consumível pelos animais), no total de quatro amostras (unidades amostrais) por subparcela, colhidas de forma sistematizada na área, tendo-se usado uma moldura de um metro de lado. Cóser et al. (2003) estudaram métodos para estimativa de forragem e concluíram que o pastejo simulado apresenta alta confiabilidade para a estimativa da forragem potencialmente consumível (acima da altura do resíduo), em pastagem de capim-elefante. Além disso, esta técnica também foi utilizada para a estimativa da quantidade de forragem, em pastagem de capim-elefante, por outros autores (Aroeira et al., 1999; Cóser et al., 1999; Deresz, 2001; Deresz et al., 2001; Carvalho et al., 2005). Após a amostragem pela técnica do pastejo simulado, foram colocadas novilhas apenas para consumir o remanescente de forragem não colhida, tendo-se mantido o pastejo até as plantas atingirem alturas de 80 a $100 \mathrm{~cm}$.

A partir de 15/10 de cada ano, mais cinco amostragens (26/10, 25/11, 27/12, 25/1 e 1\%/3) foram realizadas com o método do corte, além da técnica do pastejo simulado. Para o método do corte, também foi usada a amostragem do tipo sistemática, tendo-se adotado um quadrado de um metro de lado. No método do corte, foram coletadas quatro amostras por subparcela, cortadas a $10 \mathrm{~cm}$ acima da superfície do solo, operação repetida a cada 60 dias. As amostras foram levadas à estufa de circulação forçada de ar, a $55^{\circ} \mathrm{C}$, por 72 a 96 horas, para determinação da massa de matéria seca.

Para ambos os métodos de amostragem, foi medida a altura das plantas, tendo-se usado uma régua graduada a intervalos de $5 \mathrm{~cm}$, e tendo-se estimado a cobertura do solo por meio de estimativa visual, no total de dez amostras por subparcela.

Nas amostras colhidas pelos dois métodos, foram determinados os teores de proteína bruta (PB) e fibra em detergente neutro (FDN), além da digestibilidade in vitro da matéria seca (DIVMS), segundo procedimentos descritos por Silva \& Queiroz (2002).

Os dados de altura de planta, cobertura do solo, produção de matéria seca e dias de antecipação do pastejo foram analisados por meio do procedimento de modelo misto, pela metodologia REML, por meio do modelo com os efeitos fixos (data de início de irrigação, repetição, métodos de amostragem e datas de avaliação) e ano e erro, aleatórios (SAS Institute, 2001). Para PB, FDN e DIVMS foram realizadas as análises de variância, com as médias comparadas pelo teste de Tukey, a 5\% de probabilidade. 


\section{Resultados e Discussão}

A produção média de MS de capim-elefante, considerando-se as avaliações de julho a outubro, pela técnica do pastejo simulado, variou conforme a interação $(\mathrm{p}<0,01)$ data de início de irrigação $\mathrm{x}$ data de avaliação (Figura 1), e não se observou diferença $(p>0,05)$ entre anos nem interação deste com os demais fatores. Na maioria das datas de avaliação, foram observadas maiores produções nos tratamentos em que a irrigação ocorreu em 15/7, 1\%/8 e 15/8, em relação às obtidas nas demais datas de início de irrigação. Em geral, nas parcelas que não receberam irrigação, as produções de MS foram intermediárias às demais datas de irrigação, até a terceira avaliação, a partir de quando os valores obtidos foram semelhantes aos observados nas parcelas irrigadas de 1\%/9 em diante. Na última avaliação (14/10), as produções de MS obtidas nas três primeiras datas de irrigação foram superiores às obtidas nas irrigações iniciadas a partir de 15/9; valor intermediário foi observado para a irrigação iniciada em 1/9. As irrigações iniciadas em 15/7, 1/8, 15/8, 1/9, 15/09, 1\%/10 possibilitaram antecipação do período de pastejo em 42, 36, 28, 21, 16 e 2 dias, respectivamente, em relação aos tratamentos sem irrigação, o que caracterizou aumento no período de utilização da pastagem. Para as condições da Zona da Mata de Minas Gerais, a irrigação estratégica que se iniciou entre julho/agosto permitiria redução da área plantada para a produção de volumosos, para uso durante a época seca, considerando-se a possibilidade de uso antecipado do pasto entre quatro e seis semanas.

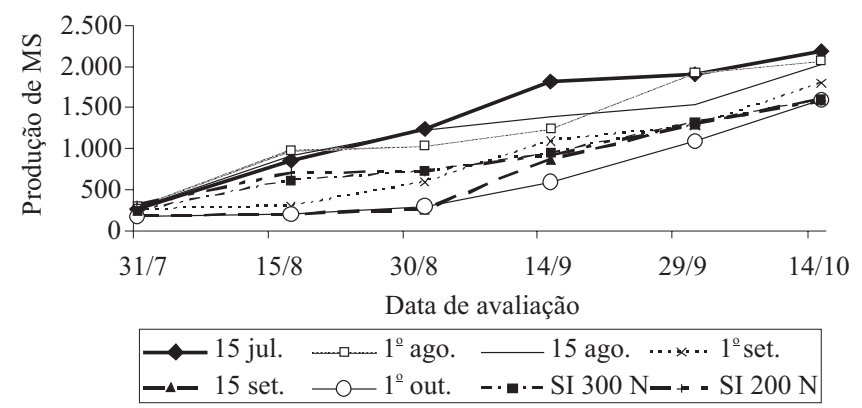

Figura 1. Produção de matéria seca $\left(\mathrm{kg} \mathrm{ha}^{-1}\right)$ de capim-elefante, na época seca (média de três anos de avaliação), em relação às datas de início de irrigação e às datas de avaliação, com uso da técnica do pastejo simulado. (SI $300 \mathrm{~N}$ - sem irrigação, com $300 \mathrm{~kg} \mathrm{ha}^{-1}$ de N por ano; SI $200 \mathrm{~N}$ - sem irrigação, com $200 \mathrm{~kg} \mathrm{ha}^{-1}$ de $\mathrm{N}$ por ano).
Houve aumento na altura das plantas, em função da interação $(p<0,01)$ entre as datas de irrigação e de avaliação (Figura 2). Foram observadas as maiores alturas de plantas nas avaliações ocorridas em 15/8, 29/9 e principalmente em 15/10, o que demonstra que a antecipação da irrigação (julho e agosto) foi efetiva em estimular o crescimento das plantas de capim-elefante.

A cobertura do solo pelas plantas foi semelhante $(\mathrm{p}>0,05)$ em todos os tratamentos (valor médio de 42,6\%), a despeito do estímulo da irrigação antecipada ao crescimento das plantas e à produção de MS. Possivelmente, a ocorrência de pequenas quantidades de chuvas, entre junho e setembro, tenha favorecido o aparecimento de novos perfilhos nas parcelas irrigadas a partir de setembro e nas do tratamento controle (sem irrigação). Tais perfilhos, ainda jovens e de pequeno tamanho, pouco contribuíram para a produção de MS, embora tenham promovido maior cobertura do solo.

Quanto à produção de MS avaliada no período chuvoso (outubro a março), quando foi usado o método do corte, além do pastejo simulado, não foi verificada diferença significativa entre os anos de avaliação, mas a interação entre as datas de irrigação e avaliação foi significativa $(p<0,01)$, conforme verificado na Figura 3 . No tratamento cuja irrigação foi iniciada em 15/7, verificaram-se maiores quantidades de matéria seca do que nos demais, com exceção das produções obtidas em dezembro e março, quando esse tratamento apresentou rendimento de matéria seca semelhante ao tratamento irrigado em 1\%/8. Ficaram caracterizados, na última data de avaliação, dois grupos de produção, em função das datas de início de irrigação, em que o de maior produção foi composto pelas datas de $15 / 7$ e $1 \% / 8$, e o de menor, pelas demais.

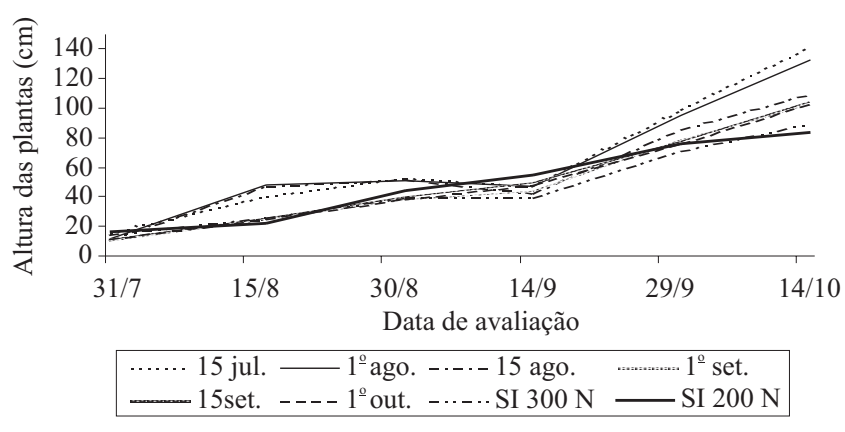

Figura 2. Altura média das plantas de capim-elefante, em relação às datas de início de irrigação e às datas de avaliação. (SI $300 \mathrm{~N}$ - sem irrigação, com $300 \mathrm{~kg} \mathrm{ha}^{-1}$ de N por ano; SI $200 \mathrm{~N}$ - sem irrigação, com $200 \mathrm{~kg} \mathrm{ha}^{-1}$ de N por ano). 
As produções de matéria seca foram influenciadas também pela interação $(\mathrm{p}<0,01)$ datas de início da irrigação $\mathrm{x}$ método de avaliação (Figura 4). Independentemente das datas de início da irrigação, as produções de matéria seca foram maiores no método do corte do que naquele do pastejo simulado, o que condiz com o tipo de amostragem realizada. No método de corte, toda a forragem existente acima de $10 \mathrm{~cm}$ do solo (colmos e folhas) foi removida, enquanto no pastejo simulado apenas folhas e pseudocolmos presentes acima da altura de resíduo foram amostrados. A despeito dos maiores valores estimados por meio do método

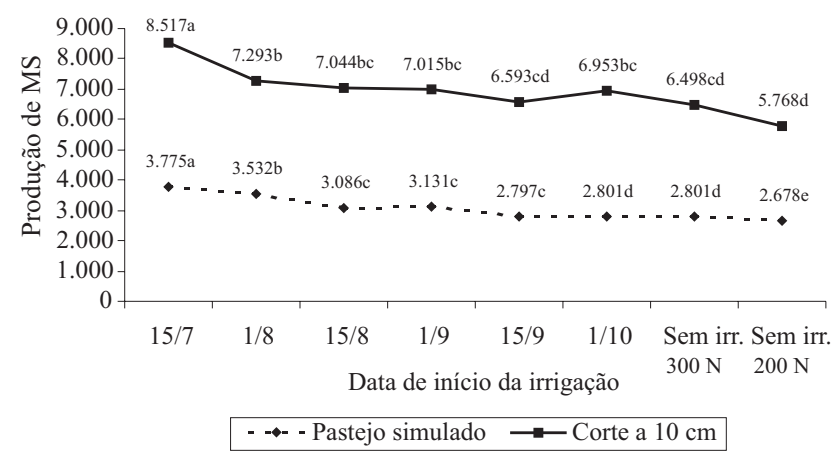

Figura 3. Produção de matéria seca $\left(\mathrm{kg} \mathrm{ha}^{-1}\right)$ de capimelefante, durante a época chuvosa (média de três anos de avaliação), em relação às datas de início de irrigação e aos métodos de avaliação, sob corte (colheitas a cada 60 dias) e pastejo simulado (colheitas a cada 30 dias, em média). Médias seguidas por letras iguais, em um mesmo método de avaliação, não diferem entre si pelo teste de Tukey, a 5\% de probabilidade.

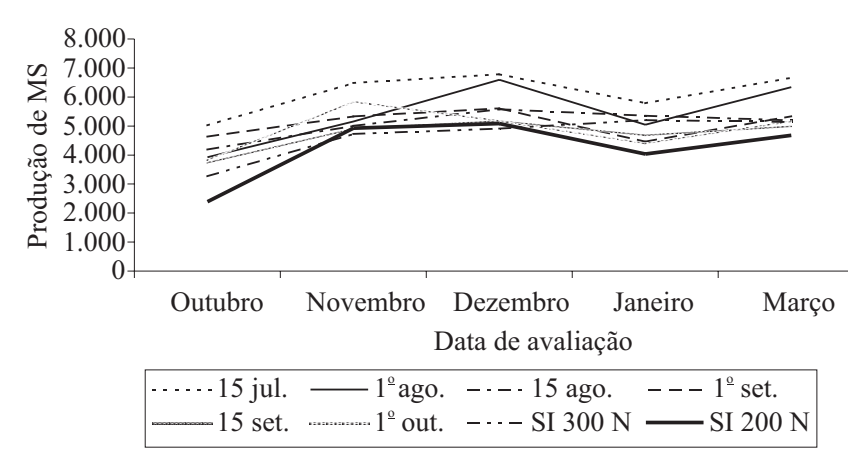

Figura 4. Produção de matéria seca $\left(\mathrm{kg} \mathrm{ha}^{-1}\right)$ de capimelefante, na época chuvosa (média de três anos de avaliação), em relação às datas de início de irrigação e às datas de avaliação (SI $300 \mathrm{~N}$ - sem irrigação, com $300 \mathrm{~kg} \mathrm{ha}^{-1}$ de N por ano, e SI $200 \mathrm{~N}$ - sem irrigação, com $200 \mathrm{~kg} \mathrm{ha}^{-1} \mathrm{de}$ $\mathrm{N}$ por ano. Dados médios obtidos pelos métodos de pastejo simulado e corte. do corte, em relação ao pastejo simulado, ressalta-se que, sob o ponto de vista de nutrição animal, a técnica de simulação de pastejo apresenta a vantagem de estimar valores próximos da biomassa potencialmente consumível por animais em pastejo, considerandose a preferência dos ruminantes em consumir folhas (Chacon et al., 1978). Nesse contexto, é possível afirmar que as quantidades de forragem estimadas permitiriam o uso de elevadas taxas de lotação animal, tendo em vista que mesmo os menores valores obtidos neste estudo foram superiores ao observados em outros trabalhos com capim-elefante sob pastejo, manejado com 4 a 5 vacas por hectare (Deresz, 2001; Deresz et al., 2001; Carvalho et al., 2005).

O tratamento cuja irrigação foi iniciada em 15/7 apresentou maior produção média de forragem, em comparação aos demais, independentemente do método de amostragem (Figura 4). Em geral, as produções médias de MS, durante o período chuvoso, diminuíram progressivamente com o avanço da data de início das irrigações. Este fato indica que houve um reflexo positivo das irrigações, realizadas de forma antecipada (julho/agosto), sobre o crescimento do capim-elefante na época das chuvas. Tanto o aumento da produção de matéria seca quanto o de a altura das plantas, proporcionados pelas irrigações antecipadas, podem ter favorecido o crescimento posterior do capim-elefante, durante o período chuvoso. Da mesma forma, Amaral (2007) observou, durante o período das chuvas, maiores massas de forragem em pastagens irrigadas durante a seca, quando comparadas àquelas não irrigadas.

Para as variáveis $\mathrm{PB}, \mathrm{FDN}$ e DIVMS não houve diferenças significativas $(p>0,05)$ quanto às datas de início da irrigação e suas interações com métodos e datas de avaliação; entretanto houve efeito $(\mathrm{p}<0,01)$ dos métodos em relação às variáveis PB e DIVMS.

A técnica do pastejo simulado apresentou valores médios de PB e DIVMS mais elevados que os obtidos pelo método do corte (Tabela 2). Os maiores valores

Tabela 2. Teores de proteína bruta (PB) e fibra em detergente neutro (FDN) e digestibilidade in vitro da matéria seca (DIVMS) de capim-elefante, avaliado sob cortes e pela técnica do pastejo simulado (Psim) $)^{(1)}$.

\begin{tabular}{lccc}
\hline Métodos & PB (\% da MS) & FDN (\% da MS) & DIVMS (\%) \\
\hline Corte & $8,6 \mathrm{~B}$ & $65,5 \mathrm{~A}$ & $59,9 \mathrm{~B}$ \\
Psim & $12,8 \mathrm{~A}$ & $66,2 \mathrm{~A}$ & $64,7 \mathrm{~A}$ \\
\hline
\end{tabular}

${ }^{(1)}$ Médias seguidas por letras iguais, nas colunas, não diferem entre si pelo teste $\mathrm{F}$, a $5 \%$ de probabilidade. 
de PB $(12,8 \%$ x 8,6\%) e DIVMS $(64,7 \%$ x 59,9), observados na avaliação pelo pastejo simulado, são resultantes da técnica que possibilita a remoção manual de folhas e pseudocolmos macios, forragem potencialmente consumível pelos animais e de maior qualidade, enquanto o corte remove toda a parte aérea da planta, composta não somente por folhas e pseudocolmos, mas também por colmos maduros. Ainda assim, os valores mínimos de PB $(8,6 \%)$ e DIVMS (59,9\%), em amostras colhidas pelo método do corte, encontram-se acima dos mínimos de 7 e $49 \%$ para PB e DIVMS, respectivamente, preconizados por Mertens et al. (1987) para um consumo voluntário adequado da forragem, e são suficientes para a manutenção animal, além de possibilitarem razoáveis ganhos em produção animal. Para o National Research Council (2001), os valores de PB (12,8\%) e DIVMS (64,7\%), obtidos pelo pastejo simulado, possibilitariam ganhos próximos de $1 \mathrm{~kg}$ por animal por dia e produções de leite de aproximadamente $12 \mathrm{~kg}$ por vaca por dia, estimativas semelhantes aos resultados observados por Deresz (2001) e Deresz et al. (2001), em pesquisas com capimelefante cultivar Napier.

Com relação à FDN, não se observou diferença significativa $(\mathrm{p}>0,05)$ entre os dois métodos de avaliação. Embora os resultados de Carvalho et al. (2005) também tenham mostrado teores de FDN de folhas de capim-elefante, semelhantes aos de colmos, este resultado pode ser considerado surpreendente, quando comparado aos de outros autores, relativos a gramíneas tropicais (Ribeiro et al., 1999; Andrade et al., 2000; Paciullo et al., 2001), os quais verificaram maiores teores de FDN nos colmos em relação às folhas. No entanto, Deschamps (1999) concluiu que até as quatro semanas após o corte, colmos e folhas apresentaram valores nutricionais semelhantes e que, após esse período, as folhas superaram os colmos, o que evidencia a existência de interação entre a idade das plantas e a fração avaliada.

\section{Conclusões}

1. A irrigação em pastagem de capim-elefante, a partir de julho e agosto, aumenta a altura das plantas e a produção de matéria seca, em relação às pastagens irrigadas a partir de setembro ou às não irrigadas.

2. A estratégia de se iniciar a irrigação de pastagem de capim-elefante a partir de julho e agosto aumenta o período de utilização anual do pasto, pela antecipação do pastejo durante a época seca, entre quatro e seis semanas.
3. Os teores de proteína bruta, fibra em detergente neutro e a digestibilidade in vitro da matéria seca do capim-elefante não se modificam com o uso de irrigação, durante o período seco do ano.

4. O método do pastejo simulado possibilita maiores valores de proteína bruta e digestibilidade in vitro da matéria seca da forragem de capim-elefante do que o método do corte, sem qualquer influência sobre os teores de fibra em detergente neutro.

\section{Agradecimentos}

Ao Conselho Nacional de Desenvolvimento Científico e Tecnológico, pelo apoio financeiro.

\section{Referências}

AMARAL, A.G. Massa seca de forragem, composição morfológica e composição bromatológica de cinco gramíneas tropicais submetidas a duas doses de nitrogênio e potássio, sob irrigação e sequeiro. 2007. 75p. Dissertação (Mestrado) Universidade Federal de Goiás, Goiânia.

ANDRADE, A.C.; FONSECA, D.M. da; GOMIDE, J.A.; ALVAREZ VENEGAS, V.H.; MARTINS, C.E.; SOUZA, D.P.H. de. Produtividade e valor nutritivo do capim-elefante cv. Napier sob doses crescentes de nitrogênio e potássio. Revista Brasileira de Zootecnia, v.29, p.1589-1595, 2000.

ALENCAR, C.A.B. Sistema de produção de leite, cana-deaçúcar e pasto, irrigado por aspersão de baixa pressão. Glória Rural, v.3, p.13-19, 1999.

AROEIRA, L.J.M.; LOPES, F.C.F.; DERESZ, F.; VERNEQUE, R.S.; MATOS, L.L.; MALDONADO-VASQUEZ, H.; VITTORI, A. Pasture availability and dry matter intake of lactating crossbred cows grazing elephantgrass (Pennisetum purpureum Schum.). Animal Feed Science and Technology, v.78, p.313-324, 1999.

BOTREL, M. de A.; ALVIM, M.J.; XAVIER, D.F. Efeito da irrigação sobre algumas características agronômicas de cultivares de capim-elefante. Pesquisa Agropecuária Brasileira, v.26, p.1731-1736, 1991.

CARVAlHO, C.A.B. de; DERESZ, F.; ROSSIELLO, R.O.P.; PACIULLO, D.S.C. Influência de intervalos de desfolha e de alturas do resíduo pós-pastejo sobre a produção e a composição da forragem e do leite em pastagens de capim-elefante. Boletim da Indústria Animal, v.62, p.177-188, 2005.

CHACON, E.A.; STOBBS, T.H.; DALE, M.B. Influence of sward characteristics on grazing behaviour and growth of Hereford steers grazing tropical grass pasture. Australian Journal of Agriculture Research, v.29, p.89-102, 1978.

CÓSER, A.C.; MARTINS, C.E.; DERESZ, F.; FREITAS, A.F. de; PACIULLO, D.F.C.; SALVATI, J.A.; SCHIMIDT, L.T. Métodos para estimar a forragem consumível em pastagem de capim-elefante. Pesquisa Agropecuária Brasileira, v.38, p.875-879, 2003. 
CÓSER, A.C.; MARTINS, C.E.; FONSECA, D.M. da; SALGADO, L.T.; ALVIM, M.J.; TEIXEIRA, F.V. Efeito de diferentes períodos de ocupação da pastagem de capim-elefante sobre a produção de leite. Pesquisa Agropecuária Brasileira, v.34, p.861-866, 1999.

DERESZ, F. Influência do período de descanso da pastagem de capimelefante na produção de leite de vacas mestiças Holandês-Zebu. Revista Brasileira de Zootecnia, v.30, p.461-469, 2001.

DERESZ, F.; LOPES, F.C.F.; AROEIRA, L.J.M. Influência de estratégias de manejo em pastagem de capim-elefante na produção de leite de vacas Holandês x Zebu. Arquivo Brasileiro de Medicina Veterinária e Zootecnia, v.53, p.482-491, 2001.

DESCHAMPS, F.C. Implicações do período de crescimento na composição química e digestão dos tecidos de cultivares de capimelefante (Pennisetum purpureum Schumach.). Revista Brasileira de Zootecnia, v.28, p.1358-1369, 1999.

DIAS FILHO, M.B.; CORSI, M.; CUSATO, S.; CAMARÃO, A.P. Digestibilidade in vitro da matéria orgânica e teor de proteína bruta em Panicum maximum Jacq. cv. Tobiatã sob estresse hídrico. Pesquisa Agropecuária Brasileira, v.26, p.1725-1729, 1991.

GERDES, L.; WERNER, J.C.; COLOZZA, M.T.; POSSENTI, R.A.; SCHAMASS, E.A. Avaliação de características de valor nutritivo das gramíneas forrageiras Marandu, Setária e Tanzânia nas estações do ano. Revista Brasileira de Zootecnia, v.29, p.955-963, 2000.

LOPES, R. dos S.; FONSECA, D.M. da; OLIVEIRA, R.A. de; NASCIMENTO JÚNIOR, D. do N.; ANDRADE, A.C.; STOCK, L.A.; MARTINS, C.E. Disponibilidade de matéria seca em pastagens de capim-elefante irrigadas. Ciência e Agrotecnologia, v.27, p.1388-1394, 2003.

MERTENS, D.R. Predicting intake and digestibility using mathematical models of ruminal function. Journal of Animal Science, v.64, p.1548-1558, 1987.
NATIONAL RESEARCH COUNCIL. Nutrient requirements of dairy cattle. 7.ed. Washington: National Research Council, 2001. $381 \mathrm{p}$.

PACIULLO, D.S.C.; GOMIDE, J.A.; QUEIROZ, D.S.; SILVA, E.A.M. da. Composição química e digestibilidade in vitro de lâminas foliares e colmos de gramíneas forrageiras, em função do nível de inserção no perfilho, da idade e da estação de crescimento. Revista Brasileira de Zootecnia, v.30, p.964-974, 2001. Suplemento 1.

PALIERAQUI, J.G.B. Influência da irrigação sobre a disponibilidade, composição química, digestibilidade e consumo das forrageiras tropicais Panicum maximum cv. Mombaça e Pennisetum purpureum cv. Napier. 2004. 58p. Dissertação (Mestrado) - Universidade Estadual do Norte Fluminense, Campos dos Goytacazes.

RASSINI, J.B. Período de estacionalidade de produção de pastagens irrigadas. Pesquisa Agropecuária Brasileira, v.39, p.821-825, 2004.

RIBEIRO, E.G. Influência da irrigação na produção de matéria seca e valor nutritivo das forrageiras Panicum maximum Jacq. e Pennisetum purpureum Schum. e no ganho de peso de novilhos Europeu-Zebu. 2004. 89p. Tese (Doutorado) - Universidade Estadual do Norte Fluminense, Campos dos Goytacazes.

RIBEIRO, K.G.; GOMIDE, J.A.; PACIULLO, D.S.C. Adubação nitrogenada do capim-elefante cv. Mott: valor nutritivo ao atingir 80 e $120 \mathrm{~cm}$ de altura. Revista Brasileira de Zootecnia, v.28, p.1194-1202, 1999.

SAS INSTITUTE. SAS/STAT: user's guide version 8.1. Cary: SAS Institute, 2001. 943p.

SILVA, D.J.; QUEIROZ, A.C. Análise de alimentos: métodos químicos e biológicos. 2.ed. Viçosa: UFV, 2002. 235p.

$\overline{\text { Recebido em } 18 \text { de abril de } 2008 \text { e aprovado em } 10 \text { de outubro de } 2008}$ 
